\title{
Severity of depression, anxious distress and the risk of type 2 diabetes - a population- based cohort study in Sweden
}

\author{
Anna Deleskog ${ }^{1 *} \mathbb{D}$, Rickard Ljung ${ }^{1}$, Yvonne Forsell $^{2}$, Alicia Nevriana $^{2}$, Aysha Almas $^{2,3}$ and Jette Möller ${ }^{2}$
}

\begin{abstract}
Background: Previous studies assessing the relationship between depression and diabetes mellitus did not consider the severity of depression. In the present study we assessed the risk of developing type 2 diabetes mellitus (T2DM) among people with various severity of depression.

Methods: This prospective longitudinal cohort study included 9,936 individuals residing in Stockholm County, Sweden who responded to the baseline questionnaire in 1998-2000. The participants were followed from 1 year after the baseline up to 2015 for the occurrence of T2DM, using the National Patient Register, Swedish Prescribed Drug Registers, and Cause of Death Register. Depression and anxious distress were assessed using psychiatric rating scales and defined according to the Diagnostic and Statistical Manual of Mental Disorders (DSM-5).

Results: Depression was associated with a statistically significant increased risk of T2DM after adjusting for potential confounders (OR 1.48, $\mathrm{Cl} 1.10,1.99)$. The strongest association was observed for severe depression (OR 1.72, Cl 1.15, 2.59). Further, those with depression, regardless of severity, and with concurrent moderate/severe anxious distress had an increased risk of T2DM (OR 1.73, Cl 1.13,2.63) compared to those with neither depression nor anxious distress.
\end{abstract}

Conclusions: The study adds evidence that depression is associated with a higher risk for developing T2DM, and the association is stronger among people with severe depression.

Keywords: Type 2 diabetes, Depression, Anxiety, Longitudinal data

\section{Background}

Depression is one of the leading cause of disability worldwide and it is a serious disorder linked to diminished quality of life, medical morbidity and mortality with a lifetime prevalence ranging from approximately 7.8 to $14.8 \%[1,2]$. However, the prevalence of depression has been reported to be higher and almost doubled among people with type 2 diabetes mellitus (T2DM) [3]. Additional to several well known risk factors for developing T2DM, such as obesity, physical inactivity, sedentary lifestyle, and high fat intake, it has also been suggested that depression plays a role for an increased risk of T2DM $[4,5]$. This has previously been shown in meta-analyses [5-8]. Furthermore, findings from a meta-

\footnotetext{
* Correspondence: deleskog.anna@gmail.com

${ }^{1}$ Institute of Environmental Medicine, Unit of Epidemiology, Karolinska Institutet, SE 171 77, Stockholm, Sweden

Full list of author information is available at the end of the article
}

analysis of cross-sectional, population-based studies suggest a positive association between depressive symptoms and insulin resistance [9]. A potential pathophysiological mechanism linking depression to T2DM is that depression increases the activity of the hypothalamus pituitary adrenal axis (HPA) and the sympathetic system leading to increased cortisol and adrenaline/noradrenaline as well as pro-inflammatory cytokines $[10,11]$. These stress hormones have various metabolic effects and that can result in insulin resistance and subsequent T2DM $[6,10$, 12]. However, increased HPA axis activity might not be the only potential mechanism between depression and increased risk of T2DM. Several studies have found that the use of antidepressant medications are associated with increased risk of T2DM, possibly through its effect on weight gain $[13,14]$. Despite many studies done to investigate the relationship between depression and T2DM, there is only a limited amount of longitudinal

(c) The Author(s). 2019 Open Access This article is distributed under the terms of the Creative Commons Attribution 4.0 International License (http://creativecommons.org/licenses/by/4.0/), which permits unrestricted use, distribution, and 
studies taking into account the severity of depression to the risk of T2DM. Moreover, no known study has considered depression with anxious distress, which is a recent specifier for depression in the Diagnostic and Statistical Manual of Mental Disorders (DSM-5), with the risk of T2DM. It has been known that depression with anxious symptoms is associated with poorer health outcomes [15].In this population-based cohort study, we aimed to assess the association between depression and anxious distress and the risk of T2DM and to assess the association of severity of depression and concomitant symptoms of anxious distress.

\section{Methods}

\section{Participants}

Data were derived from the PART study, a longitudinal cohort study of mental health (In Swedish short for Psykisk hälsa, Arbete och RelaTioner). The PART study included 10,441 individuals aged 20-64 years residing in Stockholm County, Sweden. Recruitment procedures, representativeness of the cohort and the study protocol have been described in detail elsewhere $[16,17,18]$. In brief, during the study period (1998-2015), postal questionnaires on depression and factors related to mental health were sent to the participants in three waves: wave 1 (1998-2000), wave 2 (2001-2003) and wave 3 (2010). Participants who reported diabetes in wave 1 or 2 and participants with missing ID and/or questionnaire date were excluded $(N=413)$ (Fig. 1). Data from the remaining participants were then linked to 83 the $\mathrm{Na}$ tional Patient Register, Swedish Prescribed Drug 84 Register, and Cause of Death Register using the Swedish 85 personal identification number [19-21]. Using these registers, participants were followed from 1 year after the PART questionnaire assessment (in wave 1) until T2DM occurred, death, or 31 December 2015, whichever came first. We excluded participants with T1DM, participants diagnosed with T2DM in the immediate first year after the questionnaire date, participants with missing information on depression, and participants that died before the start of follow up $(N=92)$, leaving 9,936 participants as the final cohort. The average time between the start of follow-up to the first diagnosis of T2DM was 9.43 years. Figure 1 provides a detailed illustration of the participants' selection. The study was approved by the Regional Ethical Review Board in Stockholm, Sweden (case number: 96-260, 01-218, 03-

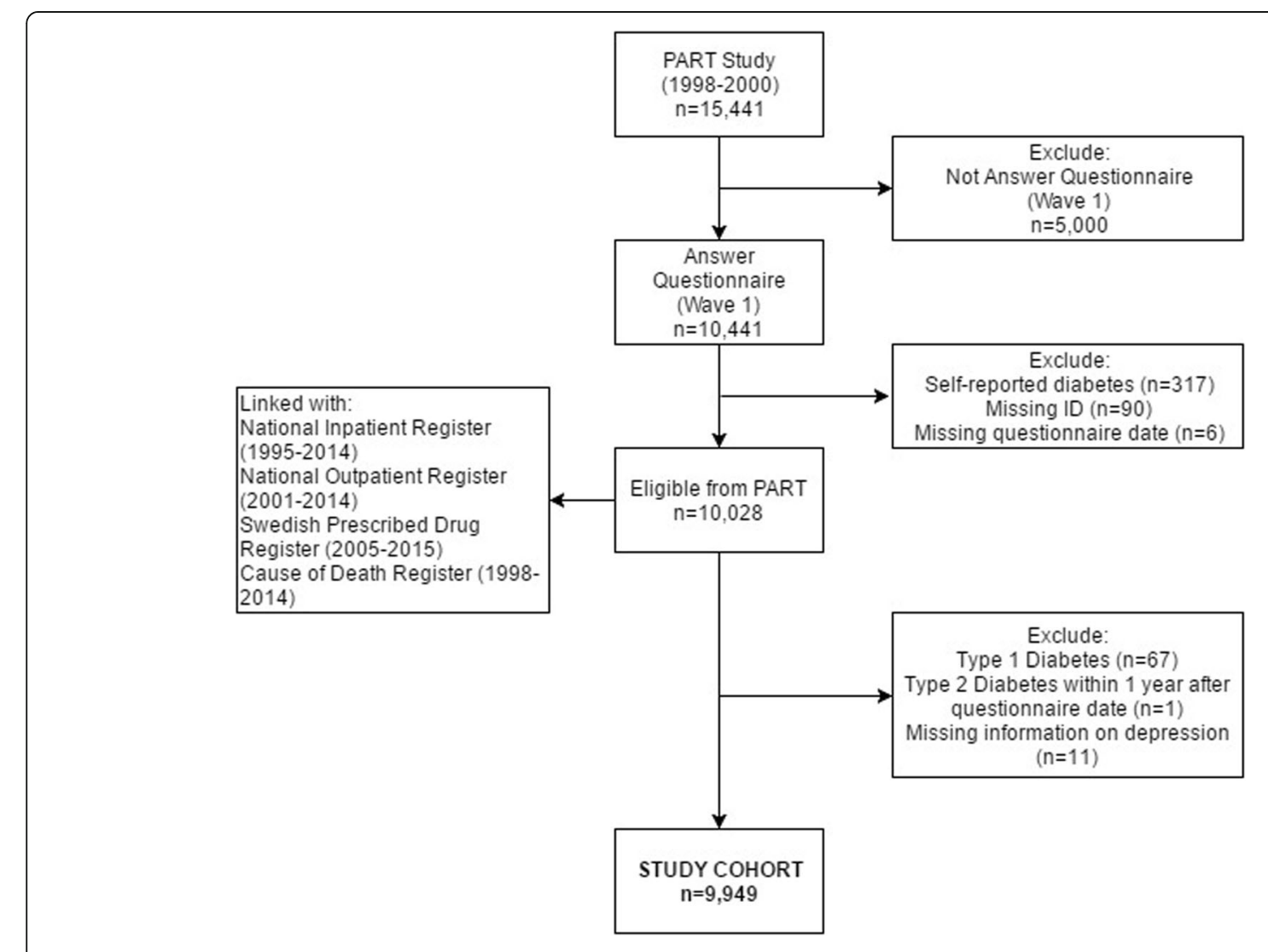

Fig. 1 Study population 
302, 2009/880-31, 2012/808-32). All participants gave their informed consent to participation.

\section{Exposure of depression and anxiety distress}

In the PART study depression was evaluated using the Major Depression Inventory (MDI) and in the current study, as well as in previous publications $[16,17,18]$, based on the responses given in wave 1 and wave 2 . If a participant was depressed in both waves, the wave in which the MDI score was highest was used to determine the level severity. The MDI has shown high validity in clinical and non-clinical samples. [22]. The MDI scale consisted of 10 questions on symptoms present "nearly every day" during the previous 2 weeks. For each question there was five response alternatives scored from 1 to 5 according to the presence of the symptom: all the time (5), most of the time (4), slightly more than half of the time (3), slightly less than half of the time (2), some of the time (1) and never (0). The score on the 10 questions was summarized ranging from 0 to 50 [23]. Severity of depression was based on the MDI score and categorized as follows: not depressed (MDI score <20), mild (20-24), moderate (25-29) and severe depression $(\geq 30)$ [24]. The PART study was extensive and included multiple scales to assess mental health. Anxious distress was based on specific items corresponding to the DSM5 from these scales and used as a specifier for depression. The moderate-severe category was combined with severe as the severe category requires a clinical observation (i.e. assessing motor agitation). It was defined as the presence of at least two of the following symptoms for the past 2 weeks: feeling keyed up or tense, feeling unusually restless, difficulty in concentrating because of worry, fear that something awful might happen and fear of losing self-control. Each symptom was assessed using a 5- or 6-point Likert scale, and, for simplicity, the response alternatives were merged as yes or no, and rated according to the number of DSM-5 symptoms. Anxious distress was then categorized based on the number of symptoms: no anxious distress (0-1), mild (2), and moderate/severe $(\geq 3)[16,17,18]$.

\section{Outcome of T2DM}

Incident cases of T2DM were assessed 1 year after responding to the questionnaire in wave 1 . The first record of T2DM according to ICD-10 code diagnoses (E11) in the National Patient Register (data available from 1998 to 2014), inpatient care as well as specialized outpatient care was considered as an incident case. Additionally, participants with a prescription of antidiabetic drugs (ATC code A10 [25]) from 1 January 2006 onwards, without any record of T2DM in the patient register and no prescribed antidiabetic drugs July 1st to December 31st 2005 were also regarded as an incident case of T2DM. T2DM was also identified from the Cause of Death Register (data available from 1998 to 2014) using ICD-10 code (E11). Participants with recorded diabetes before the start of follow-up were excluded. Since follow up started 1 year after wave 1 questionnaire and the depression could either be measured from wave 1 or 2 , we also assured that none of the participants was diagnosed between 1 year after wave 1 and wave 2. No participant was diagnosed with T2DM within this time period.

\section{Covariates}

Age, sex and socioeconomic position were considered as potential confounders since they are associated with both depression and T2DM but does not come in the causal pathway between depression and diabetes. In addition, we considered smoking, alcohol use, physical activity and body mass index (BMI) as potential mediators, presenting different models taking these factors into account [26-31]. These factors have previously been shown to increase the risk of depression and T2DM [27-31]. While they might change as a consequence of depression, in this study, we decided to evaluate their influence as being in the pathways between depression and T2DM, as illustrated in Additional file 1: Figure S1. All these variables were measured through PART questionnaires.

Socioeconomic position was determined based on occupational status and main activity of the day in wave 1 , as categorised by the Nordic Standard Occupational Classification (NSOC) of 1989 [32]. Socioeconomic positions were further grouped into the following: unskilled/ semi-skilled workers, skilled workers, assistant non-manual workers, student, old-age or early retirement, selfemployed, and high and intermediate level salaried employees.

Smoking habits were assessed in wave 2 and participants were asked whether they smoked regularly, smoked sometimes, had stopped smoking, or had never smoked. Hazardous alcohol use was identified using the Alcohol Use Disorders Identification Test (AUDIT) tool both in wave 1 and 2 [26]. The AUDIT tool consisted of 10 questions and the score ranges from 0 to 40 [26]. In this study, the results from AUDIT were dichotomized based on Swedish cut-off point $(\geq 8$ points for men and $\geq$ 6 for women) [24].

Information on physical activity was obtained in wave 2, through the following question, "Do you exercise regularly, i.e. 2-3 times a week?" in which the participants could answer "yes" or "no". BMI $\left(\mathrm{kg} / \mathrm{m}^{2}\right)$ was calculated through self-reported weight and height in wave 1 and 2 . It was further categorised into 4 groups: underweight $(<$ $18.50)$, normal (18.50-24.99), overweight (25.00-29.99), and obese $(\geq 30.00)$ [33]. For the variables where the 
information was available in both waves (i.e. AUDIT score and BMI), the highest value was chosen to be included in the analyses.

\section{Statistical analyses}

Variables were presented as percentages or mean, (standard deviation (SD)). Missing value imputation was performed for MDI if there were 1 or 2 missing answers out of the 10 MDI questions; otherwise, the response was left as missing $(n=11(0.11 \%)$ wave 1 and $n=16$ $(0.20 \%)$ wave 2$)$. The missing answers were imputed using the mean value of the response in respective questions. A similar strategy was also applied for anxious distress, although imputation was only performed if there was only one missing answer out of the five questions. For other covariates (socioeconomic position, smoking, alcohol use, physical activity, BMI), the missing observations were grouped into a separate category ("missing"). Logistic regression models with and without adjustment for confounders were estimated for assessing the association between depression and T2DM expressed as odds ratios (OR) with 95\% confidence intervals (CI). A stepwise approach was used to assess the association between depression and T2DM; model 1 the crude association, model 2;adjusted for age and sex, model 3 adjusted for age, sex, and socioeconomic position, and model 4 further adjustment for smoking status, alcohol use, physical activity, and BMI. Those without depression were considered as the reference group. When depression and anxious distress were assessed together as an exposure, those who had neither depression nor anxious distress served as the reference.

We also performed stratified analyses by age at enrolment, where we divided the category into $<50$ years or $\geq$ 50 years. All analyses were performed using SAS 9.3.

\section{Results}

In total, 9,936 participants were followed from 1998 to 2015 (Fig. 1).

The prevalence of depression at baseline measured by MDI was $14.3 \%(n=1425)$, and $5.3 \%(n=522)$ had mild depression, 3.5\% $(n=345)$ had moderate depression and $5.6 \%(n=558)$ severe depression (Table 1). The average time between the start of follow up to the diagnosis of T2DM was 9.4 years (SD 3.04). Depression was more prevalent among women, and further individuals with depression were younger, had a higher prevalence of obesity, were more often smokers and less often reported to be physically active. At the end of the follow-up period, $4.3 \%$ of individuals with depression had developed T2DM compared with 3.6\% among individuals without depression.

Depression was in the crude model associated with future risk of T2DM (OR 1.22, CI 0.92, 1.61) and after adjustment for potential confounders, the association was statistically significant $(1.48$, CI $1.10,1.99)$ (Table 2 , model 3). After further adjustment for smoking, alcohol use, physical activity and BMI an increased risk estimate remained although statistically non-significant (1.34, CI $0.98,1.82$ ) (Table 2, model 4). In addition, participants who had severe depression had a higher risk for T2DM $(1.72$, CI 1.15, 2.59) after adjustment for potential confounders (age, sex, socioeconomic position) (Table 2, model 3). Those with moderated depression did not display an increased risk for T2DM (Table 2). Further, after considering lifestyle factors the association remained but not statistically significant $(1.49$, CI $0.97,2.28)$ (Table 2 , model 4). Similarly, those with depression, regardless of severity, and with concurrent moderate or severe anxious distress had a statistically significant increased risk of T2DM (OR 1.73, CI 1.13, 2.63) (Table 2, model 3), which remained statistically significant after taking lifestyle factors into account (Table 2, model 4).

Furthermore, since there was an effect of age, we stratified individuals by age. The results indicated that the association between depression and T2DM was only present in individuals below 50 years $(1.70, \mathrm{CI} 1.14,2.55)$ and not among those 50 years and older (1.04, CI $0.67-$ 1.61) (Table 3).

\section{Discussion}

Taking into account age and gender differences, participants with depression have a higher risk of T2DM. The association was more robust among those with severe depression but only present among those 50 years and younger. Increased risks remain after further adjustment for sociodemographic factors. When also considering lifestyle factors, increased effect estimates remain. However, the confidence intervals show no statistical significance. This can be either due to decreased power or indicating that lifestyle factors partly explain some of the association between depression and T2DM. In addition, the risk of T2DM was highest among individuals with depression who also reported moderate/severe anxious distress.

Meta-analyses supported a relationship between depressed mood and an increased incidence of T2DM [6, 8]. A recent one of 33 studies demonstrated that depressed people have 32\% increased risk for developing T2DM [5]. However, the meta-analysis included several studies where the time sequence of depressive symptoms and the incidence of diabetes was unclear [5]. Our study further supports these findings and for the sequence being depression increases the risk of T2DM.

There could be several reasons for the varied findings [34]. Participants with depression might visit their physician more often and may thus be more likely to be recognized as having T2DM. Other explanations could be 
Table 1 Characteristics of participants stratified by depression status

\begin{tabular}{|c|c|c|c|c|c|}
\hline \multirow[t]{3}{*}{ Variables } & \multirow[t]{3}{*}{ Categories } & \multirow{2}{*}{$\begin{array}{l}\text { All } \\
\text { N (9936) }\end{array}$} & \multirow{2}{*}{$\begin{array}{l}\text { Depressed } \\
\text { N (1425) }\end{array}$} & \multirow{2}{*}{$\begin{array}{l}\text { Not depressed } \\
\text { N (8511) }\end{array}$} & \multirow[t]{3}{*}{$p$-values } \\
\hline & & & & & \\
\hline & & n (\%) & n (\%) & n (\%) & \\
\hline Age at baseline & Mean (SD) & $41.1(12.4)$ & $39.1(11.9)$ & $41.4(12.5)$ & $<.0001$ \\
\hline \multirow[t]{2}{*}{ Age at baseline } & $<50$ years & $6880(69.2)$ & $1070(75.1)$ & $5810(68.3)$ & $<.0001$ \\
\hline & $\geq 50$ years & $3056(30.8)$ & $355(24.9)$ & $2701(31.7)$ & \\
\hline \multirow[t]{2}{*}{ T2DM at follow up ${ }^{a}$} & No & $9573(96.4)$ & $1364(95.7)$ & 8209 (96.5) & 0.1726 \\
\hline & Yes & $363(3.7)$ & $61(4.3)$ & $302(3.6)$ & \\
\hline Age at T2DM onset ${ }^{b}$ & Mean (SD) & $61.1(9.8)$ & $57.3(9.6)$ & $61.8(9.6)$ & $<.0001$ \\
\hline \multirow[t]{2}{*}{ Age at T2DM onset ${ }^{\mathrm{b}}$} & $<50$ years & $46(12.7)$ & $13(21.3)$ & $33(10.9)$ & $<.0001$ \\
\hline & $\geq 50$ years & $317(87.3)$ & $48(78.7)$ & $269(89.1)$ & \\
\hline \multirow[t]{2}{*}{ Sex } & Men & $4395(44.2)$ & $434(30.5)$ & $3961(46.5)$ & $<.0001$ \\
\hline & Women & $5541(55.8)$ & $991(69.5)$ & $4550(53.5)$ & \\
\hline \multirow[t]{8}{*}{ Socioeconomic position } & Unskilled and semi-skilled workers & $1148(11.55)$ & $227(15.93)$ & $921(10.82)$ & $<.0001$ \\
\hline & Skilled workers & $644(6.48)$ & $92(6.46)$ & $552(6.49)$ & \\
\hline & Assistant non-manual workers & $1398(14.07)$ & $211(14.81)$ & $1187(13.95)$ & \\
\hline & Students & $537(5.40)$ & $88(6.18)$ & $449(5.28)$ & \\
\hline & Retired & $368(3.70)$ & $108(7.58)$ & $260(3.05)$ & \\
\hline & Self-employed (other than professional) & $691(6.95)$ & $74(5.19)$ & $617(7.25)$ & \\
\hline & High and intermediate level salaried employee & $4567(45.96)$ & $477(33.47)$ & $4090(48.06)$ & \\
\hline & Missing & $583(5.87)$ & $148(10.39)$ & $435(5.11)$ & \\
\hline BMI $\left(\mathrm{kg} / \mathrm{m}^{2}\right)$ & Mean (SD) & $24.2(3.7)$ & $24.1(4.1)$ & $24.3(3.7)$ & 0.1552 \\
\hline \multirow[t]{5}{*}{ BMl } & Normal (18.50-24.99) & $6172(62.1)$ & $875(61.4)$ & $5297(62.2)$ & 0.0008 \\
\hline & Underweight $(<18.50)$ & $202(2.0)$ & $44(3.1)$ & $158(1.9)$ & \\
\hline & Overweight (25.00-29.99) & $2799(28.2)$ & $371(26.0)$ & $2428(28.5)$ & \\
\hline & Obese $(\geq 30.00)$ & $644(6.5)$ & $114(8.0)$ & $530(6.2)$ & \\
\hline & Missing & $119(1.2)$ & $21(1.5)$ & $98(1.2)$ & \\
\hline \multirow[t]{3}{*}{ Physical activity ${ }^{c}$} & Yes & $4416(44.4)$ & $533(37.4)$ & $3883(45.6)$ & $<.0001$ \\
\hline & No & $3780(38.0)$ & $661(46.4)$ & $3119(36.7)$ & \\
\hline & Missing & $1740(17.5)$ & $231(16.2)$ & $1509(17.7)$ & \\
\hline \multirow[t]{5}{*}{ Smoking } & Regular smoker & $1230(12.4)$ & $287(20.1)$ & $943(11.1)$ & $<.0001$ \\
\hline & Occasional smoker & $870(8.8)$ & $145(10.2)$ & $725(8.5)$ & \\
\hline & Ex-smoker & $2380(24.0)$ & $310(21.8)$ & $2070(24.3)$ & \\
\hline & Never smoker & $3686(37.1)$ & $452(31.7)$ & $3234(38.0)$ & \\
\hline & Missing & $1770(17.8)$ & $231(16.2)$ & $1539(18.1)$ & \\
\hline \multirow[t]{3}{*}{ Hazardous alcohol use ${ }^{d}$} & Yes & $2530(25.5)$ & $527(37.0)$ & $2003(23.5)$ & $<.0001$ \\
\hline & No & $7360(74.1)$ & $888(62.3)$ & $6472(76.0)$ & \\
\hline & Missing & $46(0.5)$ & $10(0.7)$ & $36(0.4)$ & \\
\hline \multirow[t]{4}{*}{ Severity of depression } & No & & $8511(85.7)$ & & \\
\hline & Mild & & $522(5.3)$ & & \\
\hline & Moderate & & $345(3.5)$ & & \\
\hline & Severe & & $558(5.6)$ & & \\
\hline \multirow[t]{3}{*}{ Anxious distress symptoms } & No & $7855(79.1)$ & $384(27.0)$ & 7471 (87.8) & $<.0001$ \\
\hline & Mild & $1392(14.0)$ & $499(35.0)$ & $893(10.5)$ & \\
\hline & Moderate/severe & $684(6.9)$ & $542(38.0)$ & $142(1.7)$ & \\
\hline
\end{tabular}


Table 1 Characteristics of participants stratified by depression status (Continued)

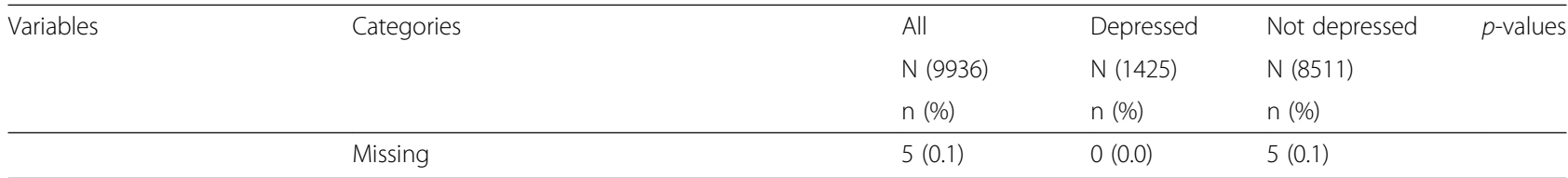

Values expressed as mean and standard deviation (SD) for continues variables or number and percentage (\%) of subjects in groups $B M I$ body mass index, T2DM Type 2 Diabetes Mellitus

${ }^{a}$ First record of T2DM using ICD-10 code (E11) in the National Patient Register more than one year after responding to the questionnaire, or anti diabetic drugs dispensation (ATC code A10) in the Swedish Prescribed Drug Registers from 1 January 2006, or T2DM recorded in the Cause of Death Register using ICD-10 code (E11)

${ }^{\mathrm{b}}$ Only persons with T2DM

'Defined as exercise regularly 2-3 times a week

${ }^{d}$ Assessed using AUDIT (The Alcohol Use Disorders Identification Test) using cut-off points $\geq 8$ for men and $\geq 6$ for women $(15,16)$

that some of the studies did not distinguish between the diagnosis of depression and depressive symptoms. Consequently, the definition of participants with depression might have varied contributing to heterogeneity. Further, different questionnaires and different cut-off levels were used to define depression and the diagnosis of diabetes was often assessed only through self-report which may lead to misclassification of exposure and outcome.

Furthermore, a recent case-control study assessing the history of depression and the prediction of T2DM showed a threefold increased risk among individuals with lifetime depression before the onset of diabetes [35]. Limitations of that study are its study design with a retrospective evaluation of depression as well as a single assessment of current depression.

The most comprehensive meta-analysis including longitudinal studies (cohort and case-control design) investigating depression as a predictor for the development of T2DM included 23 observational studies and 424,557 participants with a mean follow-up of 8.3 years showed a pooled hazard ratio of 1.38 , CI 1.23-1.55 [8]. It is worthy of note that the majority of the studies included measured depressive symptoms with self-reported questionnaires and various thresholds, and the diagnosis of diabetes was assessed only through self-report. Similarly, our study found the effects of the same magnitude. In contrast, our study was based on T2DM on clinical diagnoses in the hospital and prescribed antidiabetic medications.

Interestingly, a prospective Swedish population-based study found a 2-fold increased risk of pre-diabetes in men with depression but no effect in women for 8-10 years follow-up [36]. Moreover, previous studies investigating the association between depression and diabetes

Table 2 Association between depression status, anxious distress, and type 2 diabetes

\begin{tabular}{|c|c|c|c|c|c|}
\hline \multirow[t]{2}{*}{ Variables } & \multirow[t]{2}{*}{ Categories } & \multirow{2}{*}{$\begin{array}{l}\text { Model } 1 \\
\text { OR (95\% Cl) }\end{array}$} & \multirow{2}{*}{$\begin{array}{l}\text { Model } 2 \\
\text { OR (95\% Cl) }\end{array}$} & \multirow{2}{*}{$\begin{array}{l}\text { Model } 3 \\
\text { OR (95\% Cl) }\end{array}$} & \multirow{2}{*}{$\begin{array}{l}\text { Model } 4 \\
\text { OR }(95 \% \mathrm{Cl})\end{array}$} \\
\hline & & & & & \\
\hline \multirow[t]{2}{*}{ Depression status } & No & 1 & 1 & 1 & 1 \\
\hline & Yes & $\begin{array}{l}1.22(0.92- \\
1.61)\end{array}$ & $\begin{array}{l}1.62(1.21- \\
2.16)\end{array}$ & $\begin{array}{l}1.48(1.10- \\
1.99)\end{array}$ & $\begin{array}{l}1.34(0.98- \\
1.82)\end{array}$ \\
\hline \multirow[t]{4}{*}{ Level of depression } & No depression & 1 & 1 & 1 & 1 \\
\hline & Mild depression & $\begin{array}{l}1.20(0.77- \\
1.86)\end{array}$ & $\begin{array}{l}1.65(1.05- \\
2.60)\end{array}$ & $\begin{array}{l}1.55(0.98- \\
2.44)\end{array}$ & $\begin{array}{l}1.47(0.91- \\
2.36)\end{array}$ \\
\hline & Moderate depression & $\begin{array}{l}0.81(0.43- \\
1.54)\end{array}$ & $\begin{array}{l}1.07(0.56- \\
2.05)\end{array}$ & $\begin{array}{l}0.99(0.52- \\
1.90)\end{array}$ & $\begin{array}{l}0.90(0.46- \\
1.77)\end{array}$ \\
\hline & Severe depression & $\begin{array}{l}1.49(1.01- \\
2.20)\end{array}$ & $\begin{array}{l}1.92(1.29- \\
2.87)\end{array}$ & $\begin{array}{l}1.72(1.15- \\
2.59)\end{array}$ & $\begin{array}{l}1.49(0.97- \\
2.28)\end{array}$ \\
\hline \multirow{4}{*}{$\begin{array}{l}\text { Depression with/without levels anxious } \\
\text { distress }\end{array}$} & No depression or anxious distress & 1 & 1 & 1 & 1 \\
\hline & Depression without anxious distress & $\begin{array}{l}1.18(0.71- \\
1.98)\end{array}$ & $\begin{array}{l}1.58(0.93- \\
2.67)\end{array}$ & $\begin{array}{l}1.49(0.88- \\
2.53)\end{array}$ & $\begin{array}{l}1.29(0.75- \\
2.23)\end{array}$ \\
\hline & Depression with mild anxious distress & $\begin{array}{l}1.02(0.63- \\
1.65)\end{array}$ & $\begin{array}{l}1.32(0.81- \\
2.17)\end{array}$ & $\begin{array}{l}1.22(0.74- \\
2.00)\end{array}$ & $\begin{array}{l}1.13(0.67- \\
1.88)\end{array}$ \\
\hline & $\begin{array}{l}\text { Depression with moderate/severe anxious } \\
\text { distress }\end{array}$ & $\begin{array}{l}1.43(0.95- \\
2.13)\end{array}$ & $\begin{array}{l}1.93(1.28- \\
2.93)\end{array}$ & $\begin{array}{l}1.73(1.13- \\
2.63)\end{array}$ & $\begin{array}{l}1.58(1.02- \\
2.44)\end{array}$ \\
\hline
\end{tabular}

Logistic regression analyses with type 2 diabetes (T2DM) as the outcome variable. Cl Confidence Interval, OR Odds Ratio, MDI Major Depression Inventory Model 1 Crude 
Table 3 Association between depression status, anxious distress, and type 2 diabetes, stratified by age at enrolment

\begin{tabular}{|c|c|c|c|c|}
\hline & Model 1 & Model 2 & Model 3 & Model 4 \\
\hline & OR (95\% Cl) & OR $(95 \% \mathrm{Cl})$ & OR $(95 \% \mathrm{Cl})$ & OR $(95 \% \mathrm{Cl})$ \\
\hline \multicolumn{5}{|l|}{ Age $<50$ years } \\
\hline \multicolumn{5}{|l|}{ Depression status } \\
\hline No & 1 & 1 & 1 & 1 \\
\hline Yes & $1.71(1.16-2.51)$ & $1.90(1.29-2.80)$ & $1.70(1.14-2.55)$ & $1.56(1.03-2.38)$ \\
\hline \multicolumn{5}{|l|}{ Level of depression } \\
\hline No depression & 1 & 1 & 1 & 1 \\
\hline Mild depression & $1.44(0.77-2.70)$ & $1.61(0.86-3.02)$ & $1.49(0.79-2.81)$ & $1.57(0.81-3.02)$ \\
\hline Moderate depression & $1.41(0.65-3.06)$ & $1.55(0.71-3.38)$ & $1.42(0.65-3.11)$ & $1.31(0.58-2.95)$ \\
\hline Severe depression & $2.14(1.28-3.60)$ & $2.41(1.43-4.07)$ & $2.09(1.21-3.60)$ & $1.70(0.96-3.00)$ \\
\hline \multicolumn{5}{|l|}{$\begin{array}{l}\text { Depression with/without levels } \\
\text { anxious distress }\end{array}$} \\
\hline No depression or anxious distress & 1 & 1 & 1 & 1 \\
\hline Depression without anxious distress & $1.69(0.85-3.38)$ & $1.92(0.96-3.84)$ & $1.79(0.89-3.61)$ & $1.57(0.76-3.24)$ \\
\hline Depression with mild anxious distress & $1.51(0.81-2.83)$ & $1.64(0.87-3.07)$ & $1.48(0.78-2.80)$ & $1.40(0.72-2.72)$ \\
\hline $\begin{array}{l}\text { Depression with moderate/severe } \\
\text { anxious distress }\end{array}$ & $1.89(1.09-3.27)$ & $2.14(1.23-3.73)$ & $1.86(1.05-3.28)$ & $1.71(0.94-3.10)$ \\
\hline \multicolumn{5}{|l|}{ Age $\geq 50$ years } \\
\hline \multicolumn{5}{|l|}{ Depression status } \\
\hline No & 1 & 1 & 1 & 1 \\
\hline Yes & $1.05(0.69-1.61)$ & $1.18(0.77-1.82)$ & $1.04(0.67-1.61)$ & $0.97(0.61-1.53)$ \\
\hline \multicolumn{5}{|l|}{ Level of depression } \\
\hline No depression & 1 & 1 & 1 & 1 \\
\hline Mild depression & $1.27(0.67-2.40)$ & $1.47(0.77-2.80)$ & $1.32(0.69-2.52)$ & $1.25(0.63-2.46)$ \\
\hline Moderate depression & $0.47(0.15-1.50)$ & $0.52(0.16-1.68)$ & $0.48(0.15-1.55)$ & $0.45(0.14-1.46)$ \\
\hline Severe depression & $1.24(0.67-2.28)$ & $1.37(0.74-2.52)$ & $1.15(0.62-2.15)$ & $1.07(0.56-2.06)$ \\
\hline \multicolumn{5}{|l|}{$\begin{array}{l}\text { Depression with/without levels } \\
\text { anxious distress }\end{array}$} \\
\hline No depression or anxious distress & 1 & 1 & 1 & 1 \\
\hline Depression without anxious distress & $0.93(0.43-2.03)$ & $1.11(0.51-2.44)$ & $1.01(0.46-2.24)$ & $0.91(0.40-2.06)$ \\
\hline Depression with mild anxious distress & $0.82(0.38-1.78)$ & $0.89(0.41-1.94)$ & $0.80(0.36-1.75)$ & $0.72(0.32-1.63)$ \\
\hline $\begin{array}{l}\text { Depression with moderate/severe } \\
\text { anxious distress }\end{array}$ & $1.39(0.75-2.56)$ & $1.54(0.83-2.85)$ & $1.29(0.69-2.42)$ & $1.26(0.66-2.44)$ \\
\hline
\end{tabular}

Logistic regression analyses with type 2 diabetes (T2DM) as the outcome variable. Cl,Confidence Interval, OR Odds Ratio, MDI Major Depression Inventory Model 1 Crude

Model 2 Adjusted for sex

Model 3 Adjusted for sex and socioeconomic position

Model 4 Adjusted for sex, socioeconomic position, smoking, alcohol use, physical activity, body mass index

had indicated an increased risk among persons of younger age [37]. It is hypothesised that persons exposed to psychological stressors are more prone to develop chronic diseases at a young age [37]. Since we had a relatively young cohort with only one third above the age of 50 years at baseline, age-stratified, and fully adjusted analyses suffered from limited statistical power. However, our analyses indicated a higher risk of T2DM among persons younger than 50 (Table 1). There are possible pathophysiological mechanisms that may explain the link between depression and development of T2DM. Depression is associated with HPA axis dysregulation causing high cortisol and catecholamine levels and metabolic changes as central adiposity leading to insulin resistance, and T2DM [38, 39]. Furthermore, depressive symptoms are also associated with increased inflammation, and inflammatory markers are known in the pathophysiology of T2DM [40].

The strength of this study is the longitudinal design, the use of a population-based sample and the use of 
the MDI, a validated scale for measuring depression [21]. In addition, using the national registers, including patient and drug registers, to follow up on the outcome ensured that new cases of T2DM were identified and no participants were lost to follow-up. Another strength is that we were able to adjust for sociodemographic and T2DM risk related lifestyle factors. An alternative analytic approach to adjust for confounding is propensity score matching. We performed that as a sensitivity analysis, based on a model of age, sex, SEP, BMI, smoking and alcohol. The result did not change, and gives further robustness to our study. However, our study also has its own limitations. We used prescription of antidiabetic drugs as a proxy for T2DM diagnosis. In Sweden, antidiabetic drugs are only prescribed to those with a clinical diagnosis of diabetes and not available over-the-counter. Guidelines recommend initiation of glucose-lowering medication added to lifestyle measures in newly diagnosed patients with T2DM [41]. Therefore, if some cases were treated solely with the advice of lifestyle changes, we would misclassify some individuals as having no T2DM. This misclassification would, however, be non-differential between depressed and non-depressed. In this material we did not have reliable information about treatments for depression, which could include both pharmacological treatments, cognitive behavioural therapy as well as physical activity. Depression has been linked to weight gain, partly because of changes in lifestyle but also due to pharmacological treatment with antidepressants. Thus, it might have resulted in over or underestimation of the associations. We also measured lifestyle-related factors at one point in time and using single measurements (e.g. for physical activity), which might have led to residual confounding. We also do not know if the severity of depression might have changed or if there have been repeated episode of depression during the follow up period for the study. Future studies should pay attention to this.

In all, the present study shows a longitudinal association between depression and the incidence of T2DM for subjects aged less than 50 years and adds evidence that depression is linked to the incidence of T2DM. In addition, the findings show that depression with concurrent moderate/severe anxious distress significantly further adds to the risk of T2DM.

\section{Conclusion}

Our study suggests that people with depression, especially those with severe depression have a higher risk of T2DM. Our study highlights the importance of improving care in individuals with depressive disorders as well as anxious distress symptoms in order to prevent the potential development of T2DM.

\section{Additional file}

Additional file 1: Figure S1. Direct Acyclic Graph to inform variable. A supplementary figure to visulize with a Direct Acyclic Graph (DAG) how variables have been selected and treated in the analyses. (JPG $50 \mathrm{~kb}$ )

\section{Abbreviations \\ HPA: Hypothalamus Pituitary Adrenal Axis; MDI: Major Depression Inventory; T2DM: Type 2 Diabetes Mellitus}

\section{Acknowledgements}

Not applicable.

\section{Authors' contributions}

The study idea and study design were conceived by $A D, Y F, J M, A A$ and $R L$ and $A D$ wrote the first draft. AN performed the statistical analyses. All authors have been involved in the interpretation of the results and made important contributions to the drafting of the manuscript. All authors read and approved the final manuscript.

\section{Funding}

Funding for establishing the PART cohort data collection was provided by the Swedish Research Council, the Stockholm County Council and the Karolinska Institutet Faculty Funds (to YF).

\section{Availability of data and materials}

The datasets generated and/or analyzed during the current study are not publicly available due to confidentiality but data is accessible from the corresponding author on reasonable request.

\section{Ethics approval and consent to participate}

Research has been performed in accordance with the Declaration of Helsinki. The Ethical Review Board at Karolinska Institutet, Stockholm, approved the study (case number: 96-260, 01-218, 03-302, 2009/880-31, 2012/808-32). Written informed consent to participate in the study was obtained from participants

\section{Consent for publication}

"Not applicable".

\section{Competing interests}

The authors declare that they have no competing interests.

\section{Author details}

${ }^{1}$ Institute of Environmental Medicine, Unit of Epidemiology, Karolinska Institutet, SE 171 77, Stockholm, Sweden. ${ }^{2}$ Department of Public Health Sciences, Karolinska Institutet, SE 171 77, Stockholm, Sweden. ${ }^{3}$ Department of Medicine, Aga Khan University, Karachi, Pakistan.

Received: 22 March 2019 Accepted: 15 July 2019

Published online: 27 August 2019

\section{References}

1. James SL, Abate D, Abate KH, Abay SM, Abbafati C, Abbasi N, et al. Global, regional, and national incidence, prevalence, and years lived with disability for 354 diseases and injuries for 195 countries and territories, 1990-2017: a systematic analysis for the global burden of disease study 2017. Lancet. 2018:392:1789-858.

2. Lim GY, Tam WW, Lu Y, Ho CS, Zhang MW, Ho RC. Prevalence of depression in the community from 30 countries between 1994 and 2014. Sci Rep. 2018;8:2861.

3. Roy T, Lloyd CE. Epidemiology of depression and diabetes: a systematic review. J Affect Disord. 2012;142:S8-21.

4. Chen L, Magliano DJ, Zimmet PZ. The worldwide epidemiology of type 2 diabetes mellitus_-present and future perspectives. Nat Rev Endocrinol. 2012;8:228-36. 
5. Yu M, Zhang X, Lu F, Fang L. Depression and risk for diabetes: a metaanalysis. Can J Diabetes. 2015;39:266-72.

6. Knol MJ, Twisk JWR, Beekman ATF, Heine RJ, Snoek FJ, Pouwer F. Depression as a risk factor for the onset of type 2 diabetes mellitus. A metaanalysis. Diabetologia. 2006;49:837-45.

7. Mezuk B, Eaton WW, Albrecht S, Golden SH. Depression and type 2 diabetes over the lifespan: a meta-analysis. Diabetes Care. 2008;31:2383-90.

8. Rotella F, Mannucci E. Depression as a risk factor for diabetes. J Clin Psychiatry. 2013;74:31-7.

9. Kan C, Silva N, Golden SH, Rajala U, Timonen M, Stahl D, et al. A systematic review and meta-analysis of the association between depression and insulin resistance. Diabetes Care. 2013;36:480-9.

10. Champaneri S, Wand GS, Malhotra SS, Casagrande SS, Golden SH. Biological basis of depression in adults with diabetes. Curr Diab Rep. 2010;10:396-405.

11. Harris MD. Psychosocial aspects of diabetes with an emphasis on depression. Curr Diab Rep. 2003;3:49-55.

12. Charmandari E, Tsigos C, Chrousos G. Endocrinology of the sress response. Annu Rev Physiol. 2005;67:259-84.

13. Kivimaki M, Hamer M, Batty GD, Geddes JR, Tabak AG, Pentti J, et al. Antidepressant medication use, weight gain, and risk of type 2 diabetes: a population-based study. Diabetes Care. 2010;33:2611-6.

14. Andersohn F, Schade R, Suissa S, Garbe E. Long-term use of antidepressants for depressive disorders and the risk of diabetes mellitus. Am J Psychiatry. 2009;166:591-8.

15. Gaspersz R, Nawijn L, Lamers F, Penninx BWJH. Patients with anxious depression: overview of prevalence, pathophysiology and impact on course and treatment outcome. Curr Opin Psychiatry. 2018;31:17-25.

16. Almas A, Forsell $Y$, lqbal $R$, Janszky I, Moller J. Severity of depression, anxious distress and the risk of cardiovascular disease in a Swedish populationbased cohort. PLoS One. 2015;10:1-12.

17. Almas A, Forsell Y, Millischer V, Möller J, Lavebratt C. Association of Catechol-Omethyltransferase (COMT Val158Met) with future risk of cardiovascular disease in depressed individuals - a Swedish populationbased cohort study. BMC Med Genet. 2018;19:126. 21 Ludvigsson JF, Andersson E, Ekbom A, Feychting M, Kim J, Reuterwall C, et al. External review and validation of the Swedish national inpatient register. BMC Public Health. 2011;11:450.

18. Lundberg I, Damstrom Thakker K, Hallstrom T, Forsell Y. Determinants of non-participation, and the effects of non-participation on potential causeeffect relationships, in the PART study on mental disorders. Soc Psychiatry Psychiatr Epidemiol. 2005;40(6):475-83

19. Ludvigsson JF, Andersson E, Ekbom A, Feychting M, Kim J, Reuterwall C, et al. External review and validation of the Swedish national inpatient register. BMC Public Health. 2011;1:450.

20. Wettermark B, Hammar N, MichaelFored C, Leimanis A, Otterblad Olausson P, Bergman $U$, et al. The new Swedish prescribed drug register-opportunities for pharmacoepidemiological research and experience from the first six months. Pharmacoepidemiol Drug Saf. 2007;16:726-35.

21. Brooke HL, Talbäck M, Hörnblad J, Johansson LA, Ludvigsson JF, Druid H, et al. The Swedish cause of death register. Eur J Epidemiol. 2017;32:765-73.

22. Forsell $Y$. The major depression inventory versus schedules for clinical assessment in neuropsychiatry in a population sample. Soc Psychiatry Psychiatr Epidemiol. 2005;40:209-13.

23. Bech P, Rasmussen N-A, Olsen LR, Noerholm V, Abildgaard W. The sensitivity and specificity of the major depression inventory, using the present state examination as the index of diagnostic validity. J Affect Disord. 2001;66:159-64.

24. Snaith RP, Harrop FM, Newby DA, Teale C. Grade scores of the Montgomery-Asberg depression and the clinical anxiety scales. $\mathrm{Br} J$ Psychiatry. 1986:148:599-601.

25. WHO Collaborating Centre for Drug Statistics Methodology. ATC/DDD Index 2019. 2018. https://www.whocc.no/atc_ddd_index/. Accessed 24 Apr 2019

26. Saunders JB, Aasland OG, Babor TF, De La Fuente JR, Grant M. Development of the alcohol use disorders identification test (AUDIT): WHO collaborative project on early detection of persons with harmful alcohol consumption-II. Addiction. 1993;88:791-804

27. Källmén $H$, Wennberg P, Berman AH, Bergman H. Alcohol habits in Sweden during 1997-2005 measured with the AUDIT. Nord J Psychiatry. 2007;61:466-70

28. Flensborg-Madsen T, Bay von Scholten M, Flachs EM, Mortensen EL, Prescott E, Tolstrup JS. Tobacco smoking as a risk factor for depression. A 26-year population-based follow-up study. J Psychiatr Res. 2011:45:143-9.
29. Haynes JC, Farrell M, Singleton N, Meltzer H, Araya R, Lewis G, et al. Alcohol consumption as a risk factor for anxiety and depression. Br J Psychiatry. 2005;187:544-51.

30. Meng X, Brunet A, Turecki G, Liu A, D'Arcy C, Caron J. Risk factor modifications and depression incidence: a 4-year longitudinal Canadian cohort of the Montreal catchment area study. BMJ Open. 2017:7:e015156.

31. Hung C-F, Rivera M, Craddock N, Owen MJ, Gill M, Korszun A, et al. Relationship between obesity and the risk of clinically significant depression: Mendelian randomisation study. Br J Psychiatry. 2014;205:24-8.

32. Sweden S. Yrkesklassificeringar i FoB 85 enligt Nordisk yrkesklassificering (NYK) och Socioekonomisk indelning (SEl). Occupations in Population and Housing Census 1985 (FoB 85) according to Nordic standard occupational classification and Swedish socio-economic clas. Stockholm; 1989.

33. World Health Organization (WHO). BMI classification. Global Database on Body Mass Index. 2006. http://www.assessmentpsychology.com/icbmi.htm. Accessed 24 Apr 2019.

34. Diderichsen F, Andersen I. The syndemics of diabetes and depression in Brazil - an epidemiological analysis. SSM - Popul Health. 2019;7:100318.

35. Bruce DG, Davis WA, Hunter ML, Peters KE, Davis TME, Starkstein SE. Lifetime depression history and depression risk in type 2 diabetes: a case-control study. J Diabetes Complicat. 2016;30:38-42.

36. Eriksson A-K, Ekbom A, Granath F, Hilding A, Efendic S, stenson C-G. Psychological distress and risk of pre-diabetes and Type2 diabetes in a prospective study of Swedish middle-aged men and women. Diabet Med. 2008;25:834-42.

37. Berge LI, Riise T, Tell GS, Iversen MM, Østbye T, Lund A, et al. Depression in persons with diabetes by age and antidiabetic treatment: a cross-sectional analysis with data from the Hordaland health study. PLoS One. 2015;10:e0127161.

38. Björntorp P. Visceral fat accumulation: the missing link between psychosocial factors and cardiovascular disease? J Intern Med. 1991;230:195-201.

39. Björntorp P. Abdominal obesity and the development of noninsulindependent diabetes mellitus. Diabetes Metab Rev. 1988;4:615-22.

40. Ostenson C-G. The pathophysiology of type 2 diabetes mellitus: an overview. Acta Physiol Scand. 2001;171:241-7.

41. Davies MJ, D'Alessio DA, Fradkin J, Kernan WN, Mathieu C, Mingrone G, et al. Management of Hyperglycemia in type 2 diabetes, 2018. A consensus report by the American Diabetes Association (ADA) and the European Association for the Study of diabetes (EASD). Diabetes Care. 2018:41:2669-701.

\section{Publisher's Note}

Springer Nature remains neutral with regard to jurisdictional claims in published maps and institutional affiliations.

Ready to submit your research? Choose BMC and benefit from:

- fast, convenient online submission

- thorough peer review by experienced researchers in your field

- rapid publication on acceptance

- support for research data, including large and complex data types

- gold Open Access which fosters wider collaboration and increased citations

- maximum visibility for your research: over $100 \mathrm{M}$ website views per year

At $\mathrm{BMC}$, research is always in progress.

Learn more biomedcentral.com/submissions 